\title{
Expression of the estrogen receptor $\alpha$, progesterone receptor and epidermal growth factor receptor in papillary thyroid carcinoma tissues
}

\author{
DAN CHEN $^{1}$, WENJING QI ${ }^{1}$, PENGXIN ZHANG ${ }^{1}$, HONGWEI GUAN ${ }^{1}$ and LIFEN WANG ${ }^{2}$ \\ ${ }^{1}$ Department of Pathology, The First Affiliated Hospital of Dalian Medical University, Dalian, Liaoning 116001; \\ ${ }^{2}$ Department of Pathology, The Second Affiliated Hospital of Dalian Medical University, \\ Dalian, Liaoning 116023, P.R. China
}

Received August 2, 2014; Accepted April 17, 2015

DOI: $10.3892 / 01.2015 .3223$

\begin{abstract}
The present study aimed to determine the protein expression, in addition to the clinical value of the expression, of estrogen receptor $\alpha(E R \alpha)$, progesterone receptor (PR) and epidermal growth factor receptor (EGFR) in papillary thyroid carcinoma (PTC). The expression of ER $\alpha$, PR and EGFR was examined immunohistochemically on paraffin-embedded thyroid tissues obtained from 64 patients with PTC and 14 patients with nodular thyroid goiter (NTG). The expression level of ER $\alpha$, PR and EGFR was found to be significantly elevated in the PTC tissues compared with the NTG tissues. In addition, the expression of ER $\alpha$ was found to be correlated with the size of PTC tumors. However, there was no significant difference between the expression levels of ER $\alpha, P R$ and EGFR in males and females with PTC. Thus, immunohistochemical evaluation of ER $\alpha, P R$ and EGFR expression in patients with PTC may aid in the prediction of the prognosis of patients with PTC.
\end{abstract}

\section{Introduction}

Thyroid cancer is one of the most prevalent malignancies of the endocrine system. Papillary thyroid carcinoma (PTC), the most common histological type of thyroid cancer, has demonstrated the fastest rising incidence in previous years when compared with other endocrine cancers $(1,2)$. According to the

Correspondence to: Dr Dan Chen, Department of Pathology, The First Affiliated Hospital of Dalian Medical University, 222 Zhongshan Road, Dalian, Liaoning 116001, P.R. China

E-mail: chendan_youxiang@163.com

Dr Lifen Wang, Department of Pathology, The Second Affiliated Hospital of Dalian Medical University, 467 Zhongshan Road, Dalian, Liaoning 116023, P.R. China

E-mail: lifen_w@163.com

Key words: papillary thyroid carcinoma, estrogen receptor $\alpha$, progesterone receptor, epidermal growth factor receptor
SEER 9 database of the National Cancer Institute (Bethesda, $\mathrm{MD}, \mathrm{USA}$ ), the gender ratio of PTC in female and male patients declines from $>5$ at 20-24 years old to 3.4 at 35-44 years old, and reaches almost 1 at $>80$ years old, indicating that PTC occurs predominantly during the reproductive years (3). The predominance of PTC in females has been observed in all geographical areas and ethnic groups $(1,4)$.

As epidemiological data report a strong female predilection for thyroid cancer, the gender hormones estrogen and progesterone may play vital roles in the pathogenesis of thyroid neoplasm $(1,4)$. Estrogen and progesterone act through the estrogen receptor (ER) and progesterone receptor (PR), respectively, which belong to the nuclear hormone receptor superfamily and are expressed in benign and malignant thyroid tissues. There are two ER isoforms, ER $\alpha$, which is expressed in the endometrium, breasts, ovarian stroma and hypothalamus, and ER $\beta$, which is expressed in the kidneys, brain, bones, heart, lungs, intestinal mucosa, prostate and endothelium. PR has two isoforms, PR-A and PR-B, which are expressed in the breasts, uterus and brain (5).

Notably, it has been found that estrogen regulates the transcription of numerous cell proliferation-associated genes (6-8). In addition, accumulating evidence has revealed that estrogen exerts direct effects on thyroid cell lines originating from normal thyroid gland tissue and thyroid carcinoma by ER-dependent mechanisms, such as enhancement of proliferation, modulation of sodium-iodide symporter and thyroglobulin gene expression, and upregulation of matrix metalloproteinase (MMP) 9 production (8-10).

In PTC cells, RET/PTC re-arrangement is a common genetic event (11). A previous study has indicated that RET/PTC-induced cell growth is mediated in part by epidermal growth factor receptor (EGFR) (12). Increased expression of EGFR has been revealed to play an important role in thyroid tumor progression. Additionally, PTC stromal invasion may be regulated through EGFR-dependent activation of MMP-2/gelatinase A (13).

Generally, PTC is associated with a favorable prognosis (14-16). However, up to $10 \%$ of patients with PTC succumb as a direct result of this carcinoma, and 22-30\% experience recurrent disease $(14,16)$. Thus, it is important to be 
able to identify the PTC patients that possess a poor prognosis, through which an appropriate treatment may be chosen. The present study examined the association between immunohistochemical (IHC) factors, consisting of ER $\alpha$, PR and EGFR expression, and gender and tumor size in patients with PTC.

\section{Materials and methods}

Subjects. A total of 78 paraffin-embedded PTC tissue specimens were obtained from the Department of Pathology at the First Affiliated Hospital of Dalian Medical University (Dalian, Liaoning, China), with the specimens being excised between January 2011 and December 2013. The tissues consisted of 64 PTC tissue specimens, obtained from 27 male and 37 female patients, and 14 nodular thyroid goiter (NTG) tissue specimens, obtained from 4 male and 10 female patients. Slides stained with hematoxylin and eosin were examined initially and optimal slides were selected for IHC staining. The present study was approved by the Ethics Committee of the First Affiliated Hospital of Dalian Medical University. Written informed consent was obtained from the patients.

Immunohistochemistry. Serial tissue sections were sliced at a width of $4 \mu \mathrm{m}$ from formalin-fixed and paraffin-embedded tissue blocks, and the slices were mounted onto poly-L-lysine-coated glass slides (Thermo Fisher Scientific, Inc., Waltham, MA, USA). The sections were deparaffinized and rehydrated through a graded series of xylene-ethanol, and then incubated for $7 \mathrm{~min}$ in $3 \%$ hydrogen peroxide to inhibit endogenous peroxidases. Antigen retrieval was performed by boiling the slides for $30 \mathrm{~min}$ in EDTA ( $\mathrm{pH}$ 8.9-9.1). The tissue sections were incubated with primary rabbit anti-human monoclonal ER $\alpha$ (clone, 1D5; dilution, 1:200), rabbit anti-human monoclonal PR (clone, PgR 636; dilution, 1:250) and mouse anti-human monoclonal EGFR (clone, UMAB 95; dilution, 1:200; Dako North America, Inc., Carpinteria, CA, USA) antibodies. Immunoreactivity was assessed using the chromogen 3,3'-diamino-benzidine (Fuzhou Maixin Biotech Co., Ltd., Fuzhou, Fujian, China). The slides were then counterstained with hematoxylin, washed three times with phosphate-buffered saline for 5 min, dehydrated with graded alcohol and xylene, and mounted onto coverslips. Appropriate positive and negative controls were performed simultaneously with the patient specimen; breast carcinoma specimens were used as positive controls for ER $\alpha$ and PR, colon cancer specimens were used as the positive control for EGFR and PBS was used as the negative control.

IHC analysis. The slides were immunostained for $\mathrm{ER} \alpha$, PR and EGFR and the staining was then assessed using the scoring system reported by Allred et al (17). Briefly, the proportion score (PS) expressed the estimated proportion of tumor cells that stained positive for ER $\alpha, P R$ and EGFR, as follows: 0 , none; $1,1 / 100 ; 2,1 / 100$ to $1 / 10 ; 3,1 / 10$ to $1 / 3$; $4,1 / 3$ to $2 / 3$; and $5,>2 / 3$. The intensity score (IS) expressed the average intensity of the staining, as follows: 0, none; 1 , weak; 2 , intermediate; and 3 , strong. The PS and IS were then added to obtain a total score (TS), which ranged between 0 and 8 . Tumors were classed as positive for the expression of ER $\alpha, P R$ or EGFR if they possessed a TS $\geq 3$.
Statistical analysis. The data were analyzed using SPSS software, version 13.0 (SPSS, Inc., Chicago, IL, USA). The differences between groups were tested using the $\chi^{2}$ test. $\mathrm{P}<0.05$ was considered to indicate a statistically significant difference.

\section{Results}

Expression of ER $\alpha, P R$ and EGFR is elevated in PTC tissues. To examine whether benign and malignant thyroid cells express ER $\alpha$, PR and EGFR, IHC analysis was performed on the PTC and NTG tissue sections. Tumor cells with a score $\geq 3$ were considered to be positive for the expression of ER $\alpha$, PR or EGFR. ER $\alpha$, PR and EGFR were found to be expressed more frequently in the PTC tissues compared with NTG tissues (Fig. 1). Briefly, 38 out of 64 (59.4\%) PTC tissues demonstrated a strong immunopositivity for $\mathrm{ER} \alpha(\mathrm{P}<0.05)$, 29 out of $64(45.3 \%)$ PTC tissues demonstrated an elevated expression of PR $(\mathrm{P}<0.05)$, and 62 out of 64 (96.9\%) PTC tissues demonstrated a significantly increased expression of EGFR $(\mathrm{P}<0.05)$ (Table I).

In addition, the expression of ER $\alpha$ and PR was detected in the nucleus, while the expression of EGFR was examined in the cytoplasm and cell membrane.

ER $\alpha$ expression is increased in PTC patients with a larger tumor size. It has been reported that the tumor size is strongly associated with the therapy administered to patients with PTC and the prognosis of the patients (18). To investigate whether the expression of ER $\alpha, \mathrm{PR}$ and EGFR is also associated with the risk of PTC, the IHC data was categorized according to the size of the tumor. It was found that ER $\alpha$ expression is markedly associated with the size of PTC tumors $(\mathrm{P}<0.05)$ (Table II), indicating that ER $\alpha$ may be used as a marker to predict the risk of PTC.

Expression of ER $\alpha, P R$, and EGFR in male and female patients with PTC is not different. An increasing number of studies have revealed that the incidence of PTC is significantly increased in females compared with males $(1,3,4)$. To determine whether the expression of ER $\alpha, P R$, and EGFR is consistent with this observation, the IHC data was analyzed based on the gender of the patients. However, it was found that there was no significant difference between the expression level of ER $\alpha, \mathrm{PR}$, and EGFR in male and female patients with PTC (Table III). These data suggest that the expression level of ER $\alpha$, PR and EGFR may not be a direct causative factor for the high incidence of PTC in females.

\section{Discussion}

There are an increasing number of studies indicating that estrogen may exert a direct effect on tumorigenesis in human thyroid cells by ER-dependent or ER-independent mechanisms, through modulating cell proliferation and regulating the function of the thyroid $(8,19,20)$. The mechanistic evidence for these effects on thyroid function and growth regulation was reviewed by Santin and Furlanetto (8).

Estrogen regulates cell proliferation by binding to specific receptors, including ER. There are two isoforms of 

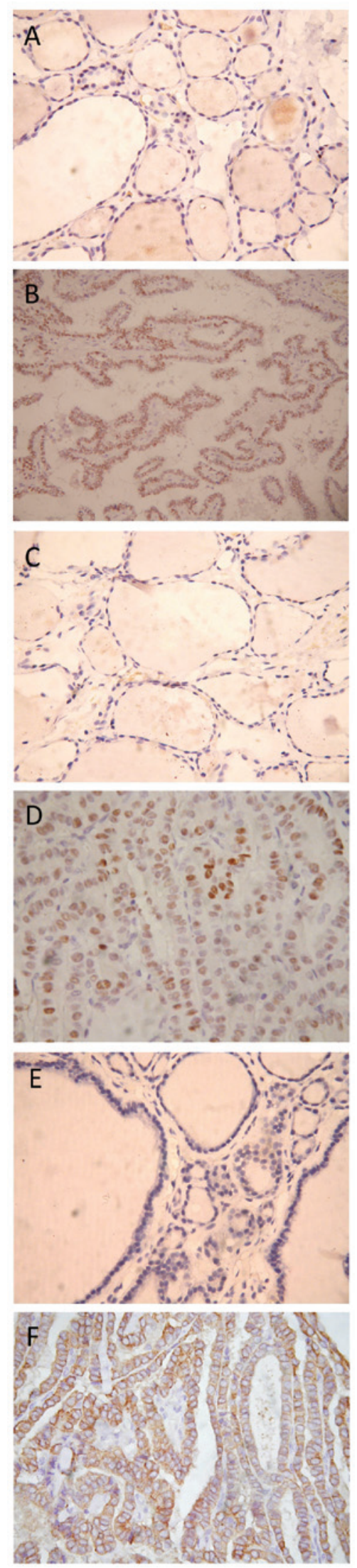

Figure 1. Immunohistochemical staining for $\mathrm{ER} \alpha, \mathrm{PR}$ and EGFR in PTC and NTG tissues. (A) NTG tissue without ER $\alpha$ staining (magnification, $x 400$ ). (B) PTC tissue with nuclear ER $\alpha$ staining (magnification, x400). (C) NTG tissue without PR staining (magnification, $\mathrm{x} 400$ ). (D) PTC tissue with nuclear PR staining (magnification, $x 400$ ). (E) NTG tissue without EGFR staining (magnification, $\mathrm{x} 400$ ). (F) PTC tissue. ER $\alpha$, estrogen receptor $\alpha$; PR, progesterone receptor; EGFR, epidermal growth factor receptor; PTC, papillary thyroid carcinoma; NTG, nodular thyroid goiter.
Table I. Increased ER $\alpha$, PR and EGFR expression by PTC tissue compared with NTG $(n=78)$.

\begin{tabular}{lcccr}
\hline & \multicolumn{2}{c}{ Tissue type, $\mathrm{n}(\%)$} & & \\
\cline { 2 - 3 } Variable & NTG & PTC & $\chi^{2}$ & P-value \\
\hline Total & $14(100.0)$ & $64(100.0)$ & & \\
ER $\alpha$ & $2(14.3)$ & $38(59.4)$ & 9.348 & 0.002 \\
PR & $1(7.1)$ & $29(45.3)$ & 7.071 & 0.008 \\
EGFR & $11(78.6)$ & $62(96.9)$ & 6.415 & 0.011 \\
\hline
\end{tabular}

ER $\alpha$, estrogen receptor $\alpha$; PR, progesterone receptor; EGFR, epidermal growth factor receptor; PTC, papillary thyroid carcinoma; NTG, nodular thyroid goiter.

Table II. Elevated ER $\alpha$ expression in papillary thyroid carcinoma patients with larger size of tumor $(n=64)$.

\begin{tabular}{lcccc}
\hline & \multicolumn{2}{c}{ Tumor size, $\mathrm{n}(\%)$} & & \\
\cline { 2 - 3 } Variable & $<1 \mathrm{~cm}$ & $>1 \mathrm{~cm}$ & $\chi^{2}$ & P-value \\
\hline Total & $33(100.0)$ & $31(100.0)$ & & \\
ER $\alpha$ & $14(42.4)$ & $19(77.4)$ & 4.904 & 0.02 \\
PR & $13(39.4)$ & $16(51.6)$ & 2.509 & 0.113 \\
EGFR & $32(97.0)$ & $30(96.8)$ & 4.799 & 0.091 \\
\hline
\end{tabular}

ER $\alpha$, estrogen receptor $\alpha$; PR, progesterone receptor; EGFR, epidermal growth factor receptor.

Table III. No difference in ER $\alpha$, PR and EGFR expression by males or females of papillary thyroid carcinoma $(n=64)$.

\begin{tabular}{|c|c|c|c|c|}
\hline \multirow[b]{2}{*}{ Variable } & \multicolumn{2}{|c|}{ Gender, n (\%) } & \multirow[b]{2}{*}{$\chi^{2}$} & \multirow[b]{2}{*}{ P-value } \\
\hline & Male & Female & & \\
\hline Total & $27(100.0)$ & 37 (100.0) & & \\
\hline $\mathrm{ER} \alpha$ & $17(63.0)$ & $21(56.8)$ & 0.249 & 0.618 \\
\hline PR & $15(55.6)$ & $14(37.8)$ & 1.977 & 0.160 \\
\hline EGFR & $27(100.0)$ & 35 (94.6) & 1.507 & 0.220 \\
\hline
\end{tabular}

ER $\alpha$, estrogen receptor $\alpha$; PR, progesterone receptor; EGFR, epidermal growth factor receptor.

$E R, E R \alpha$ and $E R \beta$. These isoforms are coded for by distinct genes and are expressed differently in human tissues during morphogenesis and in adult life $(21,22)$. The expression pattern of ER isoforms has been demonstrated in neoplastic and non-cancerous human thyroid tissues; however, the results are not consistent $(19,20)$. Experimental studies have revealed that estrogen affects PTC development by interacting with ER at the level of target thyroid cells, thereby promoting the proliferation of mutated follicular cells (23). In addition, several different thyroid cancer cell lines have been revealed 
to express ER (24-26), and the proliferation of these cells was stimulated by ER $\alpha$ agonists, and downregulated by ER $\beta$ agonists (23). Consistently, the present study revealed that the expression of ER $\alpha$ is increased in PTC tissues, compared with the expression in NTG tissues. Notably, significantly elevated expression of ER $\alpha$ was identified in PTC patients with a larger tumor size, indicating that the expression of ER $\alpha$ may be used as a predictor for an increased risk of PTC.

EGFRs are monomer cell-surface receptors that belong to the ErbB family of receptor tyrosine kinases. Mutations leading to EGFR overexpression have been associated with a variety of malignancies, including head and neck, esophageal, ovarian, cervical, lung and bladder cancers (27). In the present study, it was found that the expression of EGFR is also increased in PTC, suggesting that overexpression of EGFR may be a factor in the development of PTC.

Numerous studies have reported that the overexpression of EGFR in an anaplastic, undifferentiated subtype of PTC is associated with a high mortality rate (28-31). However, little is known about the value of EGFR expression in predicting the prognosis of thyroid carcinoma. In the present study, the clinical value of EGFR for the prediction of the risk of PTC was evaluated, although no significant association was identified between EGFR expression and the size of the PTC tumor.

In conclusion, the present study revealed that the expression levels of ER $\alpha, P R$ and EGFR were significantly elevated in PTC tissues compared with NTG tissues. In addition, the expression of ER $\alpha$ was found to correlate with the size of PTC tumors. Therefore, the results of this study indicate that immunohistochemical analyses of ER $\alpha$, PR and EGFR expression in patients with PTC may present a potential prognostic marker.

\section{References}

1. Rahbari R, Zhang L and Kebebew E: Thyroid cancer gender disparity. Future Oncol 6: 1771-1779, 2010.

2. Davies L and Welch HG: Increasing incidence of thyroid cancer in the United States, 1973-2002. JAMA 295: 2164-2167, 2006.

3. Kilfoy BA, Devesa SS, Ward MH, et al: Gender is an age-specific effect modifier for papillary cancers of the thyroid gland. Cancer Epidemiol Biomarkers Prev 18: 1092-1100, 2009.

4. Rajoria S, Suriano R, George AL, et al: Estrogen activity as a preventive and therapeutic target in thyroid cancer. Biomed Pharmacother 66: 151-158, 2012.

5. Kansakar E, Chang YJ, Mehrabi M and Mittal V: Expression of estrogen receptor, progesterone receptor, and vascular endothelial growth factor-A in thyroid cancer. Am Surg 75: 785-789, 2009.

6. Renoir JM, Marsaud V and Lazennec G: Estrogen receptor signaling as a target for novel breast cancer therapeutics. Biochem Pharmacol 85: 449-465, 2013.

7. Koos RD: Minireview: Putting physiology back into estrogens' mechanism of action. Endocrinology 152: 4481-4488, 2011.

8. Santin AP and Furlanetto TW: Role of estrogen in thyroid function and growth regulation. J Thyroid Res 2011: 875125, 2011.

9. Kamat A, Rajoria S, George A, et al: Estrogen-mediated angiogenesis in thyroid tumor microenvironment is mediated through VEGF signaling pathways. Arch Otolaryngol Head Neck Surg 137: 1146-1153, 2011.
10. Dong W, Zhang H, Li J, et al: Estrogen induces metastatic potential of papillary thyroid cancer cells through estrogen receptor alpha and beta. Int J Endocrinol 2013: 941568, 2013.

11. Lam KY, Lo CY and Leung PS: High prevalence of RET protooncogene activation (RET/PTC) in papillary thyroid carcinomas. Eur J Endocrinol 147: 741-745, 2002.

12. Croyle M, Akeno N, Knauf JA, et al: RET/PTC-induced cell growth is mediated in part by epidermal growth factor receptor (EGFR) activation: evidence for molecular and functional interactions between RET and EGFR. Cancer Res 68: 4183-4191, 2008.

13. Wells A: EGF receptor. Int J Biochem Cell Biol 31: 637-643, 1999.

14. Sherman SI: Thyroid carcinoma. Lancet 361: 501-511, 2003.

15. Lang BH, Lo CY, Chan WF, et al: Prognostic factors in papillary and follicular thyroid carcinoma: their implications for cancer staging. Ann Surg Oncol 14: 730-738, 2007.

16. Eustatia-Rutten CF, Corssmit EP, Biermasz NR, et al: Survival and death causes in differentiated thyroid carcinoma. J Clin Endocrinol Metab 91: 313-319, 2006.

17. Allred DC, Harvey JM, Berardo M and Clark GM: Prognostic and predictive factors in breast cancer by immunohistochemical analysis. Mod Pathol 11: 155-168, 1998.

18. DeLellis RA and Williams ED: Tumours of the thyroid and parathyroid. In: World Health Organization Classification of Tumours: Pathology and Genetics of Tumours of Endocrine Organs. DeLellis RA, Lloyd RV, Heitz PU and Eng C (eds). 3rd edition. IARC Press, Lyon, pp56, 2004.

19. Huang Y, Dong W, Li J, Zhang H, Shan Z and Teng W: Differential expression patterns and clinical significance of estrogen receptor- $\alpha$ and $\beta$ in papillary thyroid carcinoma. BMC Cancer 14: 383, 2014.

20. Kavanagh DO, Mcllroy M, Myers E, et al: The role of oestrogen receptor $\{$ alpha\} in human thyroid cancer: Contributions from coregulatory proteins and tyrosine kinase receptor HER2. Endocr Relat Cancer 17: 255-264, 2010.

21. Gorski J and Hou Q: Embryonic estrogen receptors: do they have a physiological function? Environ Health Perspect 103 (Suppl 7): 69-72, 1995.

22. Weihua Z, Warner M and Gustafsson JA: Estrogen receptor beta in the prostate. Mol Cell Endocrinol 193: 1-5, 2002.

23. Chen GG, Vlantis AC, Zeng Q, et al: Regulation of cell growth by estrogen signaling and potential targets in thyroid cancer. Curr Cancer Drug Targets 8: 367-377, 2008.

24. Zeng Q, Chen G, Vlantis A, et al: The contributions of oestrogen receptor isoforms to the development of papillary and anaplastic thyroid carcinomas. J Pathol 214: 425-433, 2008.

25. Zeng Q, Chen GG, Vlantis AC, et al: Oestrogen mediates the growth of human thyroid carcinoma cells via an oestrogen receptor-ERK pathway. Cell Prolif 40: 921-935, 2007.

26. Lee ML, Chen GG, Vlantis AC, et al: Induction of thyroid papillary carcinoma cell proliferation by estrogen is associated with an altered expression of Bcl-xL. Cancer J 11: 113-121, 2005.

27. Nicholson RI, Gee JM and Harper ME: EGFR and cancer prognosis. Eur J Cancer 37 (Suppl 4): 9-15, 2001.

28. van der Laan BF, Freeman JL and Asa SL: Expression of growth factors and growth factor receptors in normal and tumorous human thyroid tissues. Thyroid 5: 67-73, 1995.

29. Duh QY, Siperstein AE, Miller RA, et al: Epidermal growth factor receptors and adenylate cyclase activity in human thyroid tissues. World J Surg 14: 410-417, 1990.

30. Mizukami Y, Nonomura A, Hashimoto $\mathrm{T}$, et al: Immunohistochemical demonstration of epidermal growth factor and c-myc oncogene product in normal, benign and malignant thyroid tissues. Histopathology 18: 11-18, 1991.

31. Akslen LA, Myking AO, Salvesen H and Varhaug JE: Prognostic impact of EGF-receptor in papillary thyroid carcinoma. Br J Cancer 68: 808-812, 1993. 